Article

\title{
Leishmania infantum UBC1 in Metacyclic Promastigotes from Phlebotomus perniciosus, a Vaccine Candidate for Zoonotic Visceral Leishmaniasis
}

\author{
Jaime Larraga ${ }^{1} \mathbb{D}$, Pedro J. Alcolea ${ }^{1} \mathbb{D}$, Ana Alonso ${ }^{1}$, Luis T. C. Martins ${ }^{1}$, Inmaculada Moreno ${ }^{2}$, \\ Mercedes Domínguez ${ }^{2}$ and Vicente Larraga ${ }^{1, *(D)}$
}

1 Departamento de Biología Molecular y Celular, Centro de Investigaciones Biológicas Margarita Salas (Consejo Superior de Investigaciones Científicas), 28040 Madrid, Spain; jlarraga@cib.csic.es (J.L.); pjalcolea@cib.csic.es (P.J.A.); amalonso@cib.csic.es (A.A.); luistccm@gmail.com (L.T.C.M.)

2 Unidad de Inmunología, Centro Nacional de Microbiología, Virología e Inmunología Sanitarias (Instituto de Salud Carlos III), 28220 Majadahonda, Spain; imoreno@isciii.es (I.M.); mdominguez@isciii.es (M.D.)

* Correspondence: vlarraga@cib.csic.es

Citation: Larraga, J.; Alcolea, P.J.; Alonso, A.; Martins, L.T.C.; Moreno, I.; Domínguez, M.; Larraga, V. Leishmania infantum $\mathrm{UBC} 1$ in Metacyclic Promastigotes from Phlebotomus perniciosus, a Vaccine Candidate for Zoonotic Visceral Leishmaniasis. Vaccines 2022, 10, 231. https://doi.org/10.3390/ vaccines10020231

Academic Editor: Luigino Calzetta

Received: 14 December 2021

Accepted: 29 January 2022

Published: 3 February 2022

Publisher's Note: MDPI stays neutral with regard to jurisdictional claims in published maps and institutional affiliations.

Copyright: (C) 2022 by the authors. Licensee MDPI, Basel, Switzerland. This article is an open access article distributed under the terms and conditions of the Creative Commons Attribution (CC BY) license (https:// creativecommons.org/licenses/by/ $4.0 /)$.

\begin{abstract}
Leishmania parasites cause outstanding levels of morbidity and mortality in many developing countries in tropical and subtropical regions. Numerous gene expression profiling studies have been performed comparing different Leishmania species' life-cycles and stage forms in regard to their distinct infective ability. Based on expression patterns, homology to human orthologues, in silico HLA-binding predictions, and annotated functions, we were able to select several vaccine candidates which are currently under study. One of these candidates is the Leishmania infantum ubiquitin-conjugating enzyme E2 (LiUBC1), whose relative levels, subcellular location, in vitro infectivity in the U937 myeloid human cell model, and protection levels in Syrian hamsters against $L$. infantum infection were studied herein. LiUBC1 displays a low level of similarity with the mammalian orthologs and relevant structure differences, such as the C-terminal domain, which is absent in the human ortholog. LiUBC1 is present in highly infective promastigotes. Knock-in parasites overexpressing the enzyme increased their infectivity, according to in vitro experiments. Syrian hamsters immunized with the recombinant LiUBC1 protein did not show any parasite burden in the spleen, unlike the infection control group. The IFN- $\gamma$ transcript levels in splenocytes were significantly higher in the LiUBC1 immunized group. Therefore, LiUBC1 induced partial protection against $L$. infantum in the Syrian hamster model.
\end{abstract}

Keywords: Leishmania; vaccines; ubiquitin-conjugating enzyme E2; infection

\section{Introduction}

Leishmaniasis is a disease caused by trypanosomatid parasites from the genus Leishmania. Human leishmaniasis is classified according to the clinical manifestations into cutaneous (CL), mucocutaneous (MCL), and visceral leishmaniasis (VL), as well as according to the species involved. VL caused by Leishmania infantum is a zoonosis (ZVL), whereas VL caused by L. donovani is anthroponotic. In both cases, VL is fatal without treatment, with about 50,000 annual deaths [1]. HIV-Leishmania coinfections have been reported [2-6]. Canids are described as L. infantum (syn. L. chagasi) reservoirs in the Northern Mediterranean basin, Central Asia, and South America [7,8]. The vector in the Mediterranean basin is Phlebotomus perniciosus (Psychodidae: Phlebotominae). A human L. infantum outbreak declared more than a decade ago in central Spain is still active [9-12]. In contrast to human VL, dogs display variable cutaneous and visceral clinical signs which appear simultaneously. There are also variable profiles for the clinical signs that range from asymptomatic to severe. These include onicogriposis, weight loss, asthenia, cutaneous lesions, conjunctivitis, 
anorexia, lymphadenopathy, and hepatic splenomegaly [13,14]. Leishmania spp. parasites have a life cycle defined by two stages. The promastigotes are fusiform motile cells with a flagellum emerging from the cellular body anterior pole. This stage differentiates into the procyclic form in the sand fly gut, with low infective ability; this form then migrates towards the anterior part of the gut, transforming into a highly infective form called metacyclic. These promastigotes are inoculated in the mammalian host's dermis during blood meal intake. The promastigotes are mainly cleared by the complement system; those resistant to this action are internalized by phagocytic mononuclear cells, where they differentiate into the obligate intracellular amastigote stage and multiply. The amastigotes are released when the host cell collapses and infect other phagocytes. The sand fly be-comes infected by feeding from an infected mammal's blood, completing the parasite cycle [15].

The treatment of this disease is far from being solved. The available drugs, such as pentavalent antimonials, mitelfosine, and amphotericin B, are the first line of treatment. As a consequence of the prolonged use of these drugs, resistant parasites have emerged, resulting in clinical relapses. Another disadvantage are the side effects [16,17]. Therefore, vaccines are desirable to prevent Leishmania infections, but no vaccine against human leishmaniasis has been developed. All vaccines available against leishmaniasis confer only partial protection [18-21]. We have developed the pPAL-LACK vaccine with protection levels of approximately $60 \%$ against canine leishmaniasis [22]. This vaccine is in the final stages of evaluation by the European Medicines Agency (EMA). Its combination with other antigens may improve its efficacy. Leishmania-hamster is an appropriate infection model for VL $[23,24]$. However, the immune response has not been characterized due to the lack of available reagents for immunological studies [25].

The immune response against Leishmania spp. is partially understood, though only in mice with the L. major infection model. In this case, T helper type 1 lymphocyte response (Th1)-producing interferon- $\gamma$ (IFN- $\gamma$ ) leads to protection, whereas Th2 response leads to susceptibility [26]. In the case of the canine host, this response is more complex, with an initial increase in both Th1 and Th2 subpopulations [27]. The mechanisms responsible for counteracting the action of macrophages may be present at the promastigote stage before the infection process by the overexpression of genes responsible for encoding proteins involved in resistance mechanisms, or by the involvement of post-translational modifications of proteins participating in the resistance mechanisms. Most of the L. infantum genes are constitutively expressed throughout the differentiation processes of the parasite, and less than 5\% are differentially expressed [28]. However, proteomic studies have shown that up to $18 \%$ of the proteins appear differentially expressed among the distinct parasite stages [29]. Additionally, there is a low correlation between mRNA and protein levels [30]. Thus, both post-transcriptional and post-translational control may play an important role in the regulation of protein expression in Leishmania spp.

Previous studies in our laboratory showed the overexpression of the LinJ.33.2910 gene (www.tritrypdb.org) encoding the E2 ubiquitin-conjugating enzyme LiUBC1 in infective metacyclic promastigotes obtained from the P. perniciosus vector midgut [31,32]. This stage may be ideal for acquiring vaccine candidates. The expression profile, HLA-binding predictions, and sequence dissimilarity with mammalian orthologs suggest that this molecule may be a vaccine candidate [33].

Ubiquitin is a polypeptide that binds covalently to substrate proteins and either modifies the protein function or induces its degradation by the cell's proteasome machinery. The conjugation of ubiquitin to substrate proteins has been shown to have an essential role in controlling many cellular processes, including cell division, DNA repair, and protein synthesis [34]. The ubiquitin proteasome system is one of the main post-translational regulation mechanisms in eukaryotic cells [35]. In fact, the role of this type of protein in modifying the ubiquitination process to improve viral replication in infected cells has been described [36]. During the protein ubiquitination process, the ubiquitin-activating enzyme (E1) activates the carboxy terminus of ubiquitin. The activated ubiquitin is then transferred from E1 to the ubiquitin-conjugating enzyme (E2). Finally, the ubiquitin ligase enzyme (E3) catalyzes 
the transfer of ubiquitin from E2 to lysine amino acid residues in the substrate protein [37]. There is growing evidence for the possible relation between the downregulation of this system and the appearance of diseases related to the erroneous folding of proteins, mainly neurodegenerative diseases, such as Lewy bodies in Parkinson's disease, which display an increase in ubiquitin bound to aggregated proteins [38,39]. Despite these suggested functions, little is known about their role in cellular physiological mechanisms. Therefore, the study of ubiquitin-related proteins deserves more attention, and lower eukaryotes should provide valuable information. In fact, this protein seems to be related to the clearance of defective proteins from the cell nucleus in Saccharomyces cerevisiae [40]. Parasitic protozoa are complex unicellular organisms that undergo distinct modifications to adapt themselves to the different physicochemical environments corresponding to their distinct hosts during their biological cycles and, therefore, may be a useful model to study these regulation processes. One of the main features of Leishmania parasites are the morphological changes they undergo from the insect vector midgut to the interior of the phagocyte vacuoles in the mammalian host. These changes in shape and size require the cytoskeleton to adapt and strictly regulate the proteolysis mechanisms [41]. In fact, several processes regulated by the proteasome complex have been described in Leishmania spp. In L. donovani, it has been noted that the key enzyme methionine adenosyl transferase is negatively regulated by the proteasome complex. In the same way, ubiquitination has been associated with mRNA regulation in L. major [42] or with resistance to antimonial treatment in L. tropica [43].

The present work describes the structural modeling, relative levels, subcellular localization, and biological role in infectivity of LiUBC1, and presents evidence supporting the conclusion that LiUBC1 is a vaccine candidate that protects Syrian hamsters against $L$. infantum infection.

\section{Materials and Methods}

\subsection{Parasites and Whole Protein Extracts}

L. infantum promastigotes of the IPER/ES/2013/ATE1FL6 isolate were obtained from the stomodeal valve of P. perniciosus specimens captured during the Fuenlabrada human outbreak [9]. Promastigotes were cultured at $26{ }^{\circ} \mathrm{C}$ in Novy-Nicolle-McNeal (NNN) medium. In all cases, promastigotes were transferred to complete medium (CM) composed of RPMI 1640 supplemented with $2 \mathrm{mM}$ glutamine (Gibco BRL, Waltham, MA, USA), 10\% heat-inactivated $\left(56^{\circ} \mathrm{C}, 1 \mathrm{~h}\right.$ ) fetal bovine serum (Cambrex, East Rutherford, NJ, USA), $100 \mu \mathrm{g}$ of streptomycin, and $100 \mathrm{IU}$ penicillin/mL (Gibco BRL). Parasites were grown at $28{ }^{\circ} \mathrm{C}$. Culture samples were taken every $24 \mathrm{~h}$.

At each experimental time point, $2 \times 10^{8}$ promastigotes were centrifuged at $200 \times g$ for $5 \mathrm{~min}$ and washed three times with PBS. The sediment was resuspended in $100 \mu \mathrm{L}$ of lysis buffer (8.4 M urea, 2.4 M thiourea, $4 \%$ CHAPS $p / v, 50 \mathrm{mM}$ DTT, 1\% Triton X-100, one tablet of protease inhibitor cocktail (Roche, Basel, Switzerland), and 1 unit of DNAse (New England Biolabs, Ipswich, MA, USA)). After gently shaking for $20 \mathrm{~min}$, the mixture was centrifuged at $8000 \times g$ for $5 \mathrm{~min}$ at $4{ }^{\circ} \mathrm{C}$. The supernatant was recovered and stored at $-80{ }^{\circ} \mathrm{C}$ before use.

Peanut lectin nonagglutinating (PNA) promastigotes were obtained in stationary phase. First, they were centrifuged at $2000 \times g$ for $10 \mathrm{~min}$ in CM at a cell density of $2 \times 10^{8}$ cells $/ \mathrm{mL}$ and incubated with $50 \mu \mathrm{g} / \mathrm{mL}$ of PNA (Sigma-Aldrich, St. Louis, MO, USA) at room temperature (RT) for $30 \mathrm{~min}$. Agglutination and sedimentation was checked with light microscopy. The pellet obtained was resuspended in $1 \mathrm{~mL}$ of the remaining supernatant and taken to the initial volume of $10 \mathrm{~mL}$ with $\mathrm{CM}$ at the same concentration of PNA and centrifuged at $200 \times g$ for $10 \mathrm{~min}$. The centrifugation step was repeated to obtain the PNA+ promastigotes. The last supernatant was centrifuged at $2000 \times g$ to obtain the PNA- promastigotes. The whole process was checked by light microscopy. 


\subsection{Ethics}

All possible animal welfare measures were applied to 14 Mesocricetus auratus specimens required for the challenge experiment, such as optimal temperature, ad libitum feeding, refinement, disease follow-up, and environmental enrichment. The experimental design, the procedures, and the safety measures were approved by the Instituto de Salud Carlos III Ethical Advisory Committee for Animal Experimentation following the EU Directive 2010/63 and the Spanish regulation RD53/2013. Manipulation of rabbits was also carried out according to the animal welfare rules and supervised by the Consejo Superior de Investigaciones Científicas (CSIC) Ethical Committee (EU Directive 2010/63 and Spanish regulation RD53/2013).

\subsection{LiUBC1 Expression and Purification}

The LiUBC1 gene CDS, including an upstream 6xHis-tag coding sequence was PCRamplified (BamHI-LiUBC1-Fw 5'-TAAGGATCCCCTCTACGGCGGCT-3' and BamHILiUBC1-Rv 5'-CAAAAGCTTTCAGATGCGGCGCAGC-3') and cloned in the pQE30 expression vector using XL1-blue chemically competent cells as the recipient $E$. coli strain. E. coli M15 cells were transformed with $\mathrm{pQE30-LiUBC1}$ and a $10 \mathrm{~mL}$ preinoculum grown at $37^{\circ} \mathrm{C}$ in LB medium containing ampicillin $(100 \mu \mathrm{g} / \mathrm{mL})$ and kanamycin $(50 \mu \mathrm{g} / \mathrm{mL})$. A $0,5 \mathrm{~L}$ flask was seeded with $5 \mathrm{~mL}$ of inoculum and grown to an $\mathrm{OD}_{595}$ value of 0.5 . Heterologous expression was then induced by adding $1 \mathrm{mM}$ IPTG and incubating for $4 \mathrm{~h}$ at $37^{\circ} \mathrm{C}$. Thereafter, the bacterial cells were centrifuged at $6000 \times \mathrm{g}$ for $15 \mathrm{~min}$ at $4{ }^{\circ} \mathrm{C}$ and washed with $0.9 \% \mathrm{NaCl}$ solution. Per gram of pellet, $10 \mathrm{~mL}$ of lysis buffer $(1 \mathrm{M} \mathrm{KCl}, 60 \mathrm{mM}$ imidazole, $1 \%$ Brij $58,10 \%$ glycerol, and $1 \mathrm{mM}$ benzamidine) was added. The lysate was stored at $-80{ }^{\circ} \mathrm{C}$ until usage. Once thawed, it was centrifuged at $20,000 \times g$ for $1 \mathrm{~h}$ at $4{ }^{\circ} \mathrm{C}$. LiUBC 1 contains the $6 x$ His tag in the $\mathrm{N}$-terminus and was found mainly in the pellet, which was resuspended in $3 \mathrm{~mL}$ of $5 \mathrm{M} \mathrm{GuHCl}$ for subsequent purification in denaturing conditions. After centrifugation, the extract was subject to affinity chromatography in a 6xHis-loaded HiTrap FF 1 mL column (GE Healthcare, Little Chalfon, UK) using an FPLC ÄKTA system (GE Healthcare, Little Chalfon, UK). After washing with increasing concentrations of imidazole, 6xHis-LiUBC1 elution was performed with $700 \mathrm{mM}$ imidazole and $5 \mathrm{M} \mathrm{GuHCl}$. The purified protein fractions were analyzed by SDS-PAGE.

\subsection{Antibody Obtainment}

The specific anti-LiUBC1 polyclonal antibody was obtained using New Zealand rabbits, each inoculated with four doses of $500 \mu \mathrm{g}$ of the purified LiUBC1 protein in $0.5 \mathrm{~mL}$ PBS buffer. The LiUBC1 protein was obtained by excision of the purified band and subsequent gel diffusion after SDS-PAGE using prestained TGX gels (BioRad ${ }^{\circledR}$, Hercules, CA, USA). The initial dose was emulsified with Freund's complete adjuvant (1:1) and the following three doses with incomplete Freund's adjuvant, each inoculated at three-week intervals.

\subsection{Protein Expression Level Determination by Western Blot}

Relative expression levels of proteins between different cellular stages were carried out by Western blot experiments, according to a previously described protocol [44]. In short, previously obtained extracts from different days of promastigote culture as well as amastigote-like cells were quantified by the Bradford method [45], and $20 \mu \mathrm{g}$ of each sample was run through SDS-PAGE [46] and transferred to nitrocellulose membranes $(0.45 \mu \mathrm{m}$, BioRad labs). LiUBC1 was detected using the specific polyclonal antibody generated (1:100) and HRP-conjugated goat antirabbit IgG (1:2000) as the secondary antibody (Dako, Agilent Technologies, Santa Clara, CA, USA). A primary antibody against gGAPDH (1:10000) was used for the internal standard [47]. Detection was carried out by using an ECL Western Blotting Detection Kit (GE Healthcare) and a LAS-3000 Image Reader (GE Healthcare). 


\subsection{Generation of L. infantum LiUBC1 Knock-In Promastigote Line}

The obtainment of an L. infantum cell line overexpressing LiUBC1 was carried out with the vector pIRmcs3 [48]. The LinJ.33.2910 gene was initially cloned in the DH5 $\alpha$ E. coli strain. L. infantum promastigotes were washed in electroporation buffer (132 mM NaCl, $8 \mathrm{mM}$ $\mathrm{KCl}, 8 \mathrm{mM} \mathrm{Na}_{2} \mathrm{HPO}_{4}, 1.5 \mathrm{mM} \mathrm{KH} \mathrm{PO}_{4}, 0.5 \mathrm{mM}$ potassium acetate, $90 \mu \mathrm{M}$ calcium acetate, $\mathrm{pH} 7.0)$, sterilized by filtration $(0.22 \mu \mathrm{m})$, and resuspended in $400 \mu \mathrm{L}$ of the same buffer to a final concentration of $7 \times 10^{6}$ cells $/ \mathrm{mL}$. The electric pulse $(1 \mathrm{KV} / 24 \Omega / 28 \mathrm{~ms})$ was delivered in the presence of the linearized plasmid pIRmcs 3 containing the LiUBC1 gene (3 $\mu \mathrm{g}$ DNA). The same conditions were used with the pIRmcs3 plasmid without insert for the obtainment of a control promastigote line. During the initial $24 \mathrm{~h}$ of culture, transfected promastigotes and controls were resuspended in CM supplemented with 20\% HIFBS and $10 \%$ stationary promastigote culture medium sterilized by filtration. After $24 \mathrm{~h}, 100 \mu \mathrm{g} / \mathrm{mL}$ of the selection agent nourseothricin (Jena Bioscience, Jena, Germany) was added to the cultures. After one week, the amount of nourseothricin was increased to $120 \mu \mathrm{g} / \mathrm{mL}$ and transfected promastigotes were cultured in the presence of the antibiotic. In all experiments, promastigotes transfected with the pIRmcs3 plasmid without the LinJ.33.2910 gene were used as controls.

\subsection{LiUBC1 Cellular Detection by Indirect Immunofluorescence (IIF)}

L. infantum promastigotes $\left(2 \times 10^{5}\right)$ were sedimented onto a $0.2 \mathrm{~cm}^{2}$ area on a glass slide and fixed with $4 \%$ paraformaldehyde solution for $5 \mathrm{~min}$ at RT. After three washes with PBS in a Coplin jar for $5 \mathrm{~min}$, L. infantum promastigotes were permeabilized with a $0.5 \%$ Triton X-100 solution in PBS for 5 min. Blocking was carried out with a $0.1 \%$ solution of Tween-20 in PBS containing 5\% w/v skimmed milk in a wet chamber. Promastigotes were incubated with specific polyclonal antibody anti-LiUBC1 in blocking buffer (1:50) for $1 \mathrm{~h}$. After a single wash, cells were incubated with the secondary antibody antirabbit IgG conjugated to the fluorophore Alexa Fluor 488 (Jackson Immunoresearch, West Grove, PA, USA) (1:200) in blocking buffer for $1 \mathrm{~h}$ in the dark. Ten minutes before the end of this incubation, $10 \mu \mathrm{L}$ of $10 \mu \mathrm{g} / \mathrm{mL}$ DAPI (Thermo Fisher Scientific, Waltham, MA, USA) in PBS was added. The cells were finally washed three times with PBS in the dark and preparations were mounted with Mowiol 4-88 (Sigma-Aldrich, Burlington, MA, USA). Images were obtained in a Spectrum Laser confocal Leica TCS-SP5-OABS microscope previously adjusted to the negative control (preimmune serum 1:50).

\subsection{Transmission Electron Microscopy (TEM) Detection of LiUBC1}

Promastigotes were fixed with $2 \% p$-formaldehyde and $0.2 \%$ glutaraldehyde in $0.1 \mathrm{M}$ sodium kakodylate, $4.5 \%$ sucrose, $\mathrm{pH} 7.4$, for $30 \mathrm{~min}$ at $4{ }^{\circ} \mathrm{C}$. The samples were dehydrated in an ethanol-ethyleneglycol sequential mixture (50-100\%) in a temperature range of $0{ }^{\circ} \mathrm{C}$ to $-35^{\circ} \mathrm{C}$ at 30 min intervals. Then, promastigotes were transferred to a Lowycril $\mathrm{K} 4 \mathrm{M}$ solution in ethanol (1:1 and 1:2) and finally to pure Lowicryl K4M overnight. Subsequently, the samples were introduced into gelatin capsules and polymerized by UV light for $72 \mathrm{~h}$ and then cut with an ultramicrotome.

The promastigote preparations were incubated with the anti-LiUBC1 antibody (see Section 2.4) for $60 \mathrm{~min}$ at $37^{\circ} \mathrm{C}$. After four washes of $5 \mathrm{~min}$, the samples were incubated with antirabbit IgG secondary antibody conjugated with colloidal gold (1:10). After three additional washes with buffer containing $0.1 \%$ Triton X-100 in milliQ water, the samples were incubated with 1\% uranyle acetate in bidistilled water for $10 \mathrm{~min}$, washed twice with water for $1 \mathrm{~min}$, mounted, and observed with a JEOL JEM-1230 electron microscope.

\subsection{Mass Spectrometry LC-MS/MS Analysis}

LiUBC1 samples were dissolved in Laemmli sample buffer and run through a 10\% SDS-PAGE gel. Protein bands were excised from the gel and digested in-gel with trypsin, as described in $[49,50]$. Peptides were separated with an Easy-nLC 1000 Nano System (Thermo Fisher Scientific, Waltham, MA, USA) using a precolumn Acclaim PepMap 100 
(Thermo Fisher Scientific) and an RSLC PepMap C18, $15 \mathrm{~cm}$ long, $75 \mu \mathrm{m}$ inner diameter, and $3 \mu \mathrm{m}$ particle size column (Thermo Fisher Scientific). The flow rate was $300 \mathrm{~nL} / \mathrm{min}$ using $0.1 \%$ formic acid in water (FAW) and $0.1 \%$ formic acid in $100 \%$ acetonitrile (FAA). The gradient profile was set as follows: 0-35\% FAA for $90 \mathrm{~min}, 35-100 \%$ FAA for $4 \mathrm{~min}$, $100 \%$ FAA for $8 \mathrm{~min}$. The sample input was $4 \mu \mathrm{L}$.

A Q Exactive LC-MS/MS system (Thermo Fisher Scientific) was used to perform the MS analysis. Ionization was set at a liquid junction voltage of $1800 \mathrm{~V}$ and a capillary temperature of $270{ }^{\circ} \mathrm{C}$. The software scan method was set with $m / z$ values equal to $400-1500$, a resolution value of 70,000 for the Orbitrap analyzer (for $m / z 200$ ), target automatic gain control (AGC) equal to $3 \times 10^{6}$, and an injection time up to $100 \mathrm{~ms}$. The 10 most intense precursor ions were chosen for MS/MS fragmentation, which was performed with a normalized collision energy of $27 \mathrm{eV}$ and the following settings applied for acquisition: starting $\mathrm{m} / \mathrm{z}$ value of 100 ; AGC target of $2 \times 10^{5}$ with a $8 \times 10^{3}$ threshold; 17,500 resolution $(\mathrm{m} / \mathrm{z}$ 200); $2 \mathrm{~m} / \mathrm{z}$ isolation window; and $100 \mathrm{~ms}$ maximum IT. The ions that were unassigned, singly charged, or bore $\geq 7$ protonations were excluded from subsequent analysis, applying a dynamic exclusion time of $20 \mathrm{~s}$ to discriminate previously selected ions.

Whole protein samples were obtained on days 1,3, and 5 of growth using a lysis buffer containing 8.4 M urea, 2.4 M thiourea, 4\% w/v CHAPS, $50 \mathrm{mM}$ DTT, 1\% Triton X-100, one tablet of a protease inhibitor cocktail (Roche), and $50 \mu \mathrm{g} / \mathrm{mL}$ benzonase (Merck, Kenilworth, NJ, USA). The protein samples were precipitated with methanol:chloroform:water (4:1:3), resuspended in $50 \mathrm{mM}$ triethyl ammonium bicarbonate (TEAB), and labelled using an 8-Plex iTRAQ kit (AB SCIEX) according to manufacturer instructions. The labelled samples were grouped and purified using MCX cartridges (Waters) to remove excess ITRAQ reagent and nonpeptidic residual materials. Peptides were eluted with $1 \mathrm{~mL}$ of methanol:ammonium hydroxide (9:1), dried, and fractionated by liquid chromatography. After desalting with C18 OMIX (Agilent Technologies), samples were kept at $-80^{\circ} \mathrm{C}$ until their LC-MS/MS analysis. All peptide separation was carried out using an Easy-nLC 100 (Thermo Fisher Scientific) system. The elution stream was $300 \mathrm{~nL} / \mathrm{min}$ using formic acid in acetonitrile from $0.1 \%$ to $100 \%$. MS analysis was conducted using an OrbiTrap Mass Spectrometer (Thermo Fisher Scientific). For quantification, labeled peptide mixtures were reconstituted in formic acid 0.1\%, trapped in a precolumn Acclaim PepMap 100 (Thermo Fisher Scientific), and eluted in an Acclaim PepMap C18 column. Each analysis was carried out in duplicate.

Proteome Discoverer software (version1.4.1.14) (Thermo Fisher Scientific) was used for iTRAQ analysis. The *.raw files containing the mass spectra were analyzed with SEQUEST against the reference L. infantum JPCM5 genome, which contains 8062 protein entries. Mass tolerance was adjusted to $10 \mathrm{ppm}$ for precursors and $0.02 \mathrm{Da}$ for fragments. Other settings were 2 missed cleavages, carbamidomethylation of cysteines (fixed), methionine oxidation, and N-terminal acetylation (variable). The Percolator algorithm 9 [51] was used to filter identified peptides, setting 0.01 as q-value threshold.

\subsection{L. infantum In Vitro Infection Experiments}

The U937 cells (CRL-1593.2 ${ }^{\mathrm{TM}}$, ATCC ${ }^{\circledR}$, Manassas, Virginia, USA) were maintained in Roux flasks at $37^{\circ} \mathrm{C}$ in the presence of a $5 \% \mathrm{CO} 2$ atmosphere. On an 8-well cell culture slide, $150 \mu \mathrm{L}$ of cell suspension per well was fixed at a cell density of $2 \times 10^{8} / \mathrm{cm}^{2}$. Cells were stimulated with $20 \mathrm{ng} / \mathrm{mL}$ of phorbol myristate acetate (PMA) for $72 \mathrm{~h}$ and infections were carried out by adding wild-type and LiUBC1-transfected L. infantum promastigotes to the cell cultures at a promastigote:U937 cell ratio of 10:1 for $2 \mathrm{~h}$. After infection, cells were washed with CM. All the biological replicates were carried out in triplicate. After 24 or $48 \mathrm{~h}$, the culture slides were washed and $150 \mu \mathrm{L}$ of fixing solution (ethanol:acetic acid (3:1)) was added to each well. Wells were removed and the slides were stained with Diff-Quik solution (Dade Behring, Deerfield, IL, USA). The percentage of infected cells as well as the number of amastigotes per cell were calculated in all biological replicates by using the Student's t-test implemented in Sigmaplot 11 software $\left(\right.$ Sigmaplot $^{\circledR}$, San Jose, CA, USA). 


\subsection{Animal Challenge Experiments}

Of a total of 14 animals (M. auratus), 6 were used as controls and 8 were inoculated intraperitoneally with $20 \mu \mathrm{g}$ of recombinant LiUBC1 protein in $1 \mathrm{~mL}$ of PBS. Controls were inoculated with PBS. The second inoculation was given three weeks later. After two weeks, animals were challenged with $10^{7} \mathrm{~L}$. infantum metacyclic promastigotes (MCAN/ES98/10445) in $200 \mu \mathrm{L}$ of PBS. The animals were euthanized according to the EU rules for animal welfare (EU Directive 2010/63 and Spanish regulation RD52/2013), and spleen and blood were obtained for analysis.

\subsection{Parasite Burden Evaluation and Immune IgG Response Determination in M. auratus Model}

At the end of the challenge experiments with M. auratus, the spleens were extracted aseptically, weighed, homogenized, and resuspended in $3 \mathrm{~mL}$ of Schneider's Drosophila medium supplemented with 10\% HIFBS (HyClone, Thermo Fisher Scientific), penicillin (100 U / mL), streptomycin (50 mg/mL, Lonza $\left.{ }^{\circledR}\right)$, 20 mM HEPES (Sigma-Aldrich), and 1\% sterile urine. Four samples of the homogenized suspension were seeded and diluted six times in a 96-well plate. Plates were incubated for two weeks and parasites were detected in the well cultures by optical microscopy $(200 \times)$. Parasite burden was calculated as the geometric mean of the parasites detected at the maximum dilution described [52].

The blood sample was allowed to clot at RT for $20 \mathrm{~min}$ and was centrifuged at $10,000 \times g$ at room temperature for $10 \mathrm{~min}$. The serum was stored at $-80{ }^{\circ} \mathrm{C}$ and used later for a total IgG antibody determination against total L. infantum soluble antigen (SLA) by ELISA. First, a flat bottom plate was lined with $100 \mu \mathrm{L}$ of a $10 \mu \mathrm{g} / \mathrm{mL}$ SLA solution in $3.36 \mathrm{mM}$ carbonate-10 $\mathrm{mM}$ bicarbonate buffer overnight at $4{ }^{\circ} \mathrm{C}$. Subsequently, it was blocked with a $1 \%$ BSA solution in PBS and washed three times with a $0.1 \%$ BSA and $0.03 \%$ Tween 20 solution in PBS. Next, $100 \mu \mathrm{L}$ of a 1:20 serum sample was added to each well and left for $30 \mathrm{~min}$ at RT. Meanwhile, protein A (Sigma-Aldrich, Burlington, MA, USA) was prepared at a concentration of $0.19 \mu \mathrm{g} / \mathrm{mL}$ using a wash solution. The samples were washed before and after incubation, which was performed with $100 \mu \mathrm{L}$ of the protein $\mathrm{A}$ solution for $2 \mathrm{~h}$ at RT. The last wash was carried out with PBS. An o-phenylenediamine dihydrochloride (OPD) tablet was dissolved in $12 \mathrm{~mL}$ of citrate buffer (5.2 $\mathrm{mM}$ citric acid, $\left.12.7 \mathrm{mM} \mathrm{Na}_{2} \mathrm{HPO}_{4}, \mathrm{pH} 5\right)$ and $15 \mu \mathrm{L} \mathrm{H}_{2} \mathrm{O}_{2}$. To each well was added $100 \mu \mathrm{L}$ of said solution, and the colorimetric reaction was allowed to develop for $20 \mathrm{~min}$. The reaction was stopped by adding $50 \mu \mathrm{L}$ of a $1 \%$ SDS solution. The absorbance was read at $450 \mathrm{~nm}$ using a Microplate Reader 680 (BioRad ${ }^{\circledR}$, Hercules, CA, United States) and Microplate Manager 5.2.1 software $\left(\operatorname{BioRad}^{\circledR}\right)$.

\subsection{Relative IFN- $\gamma$ Expression Levels in Splenocytes by qRT-PCR}

Whole RNA samples were obtained using TRIzol ${ }^{\circledR}$ reagent (Life Technologies, Carlsbad, CA, USA). First-strand cDNA synthesis was performed starting from $10 \mu \mathrm{g}$ of total RNA. First, the RNA was mixed with $6 \mu \mathrm{g}$ of random hexamer primers (Life Technologies). The mixture was denatured at $70{ }^{\circ} \mathrm{C}$ for $2 \mathrm{~min}$ and immediately cooled on ice. Then, the samples were incubated at $46^{\circ} \mathrm{C}$ for $3 \mathrm{~h}$ with $570 \mu \mathrm{M}$ of each $\mathrm{dNTP}, 10 \mu \mathrm{M}$ DTT, and $600 \mathrm{U}$ SuperScript III Reverse Transcriptase (Life Technologies) in $30 \mu \mathrm{L}$ of reaction volume. Next, RNA degradation was performed using $1 \mathrm{U}$ RNaseH (Life Technologies) at $37^{\circ} \mathrm{C}$ for $30 \mathrm{~min}$. Enzyme denaturation was performed at $65{ }^{\circ} \mathrm{C}$ for $10 \mathrm{~min}$. The resulting cDNA samples were purified using QiaQuick PCR Purification Kit (Qiagen, Hilden, Germany). Syrian hamster IFN- $\gamma$ TaqMan assay no. Cg04455412_m1 (primers and FAM-NFQ MGB probe, Applied Biosystems, Waltham, MA, USA) were mixed with cDNA samples (10, 2, and $0.4 \mathrm{ng}$ cDNA per reaction set by serial dilutions) and with TaqMan Universal Master Mix $2 \mathrm{X}$ (Life Technologies) in $10 \mu \mathrm{L}$ reaction volume. Thermal cycling runs were performed in a 7900HT Fast Real-Time PCR system. Thermal cycling conditions set in SDS 4.1. software (Life Technologies) were: $95^{\circ} \mathrm{C}, 5 \mathrm{~min} ; 40 \times\left(95^{\circ} \mathrm{C}, 30 \mathrm{sec} ; 60^{\circ} \mathrm{C}, 1 \mathrm{~min}\right.$, data acquisition). The $\beta$-actin taqman assay no. Cg04424027_gH (Applied Biosystems) was used as the refer- 
ence gene for quantification using the $\Delta \Delta \mathrm{Ct}$ [53]. The Mann-Whitney $\mathrm{U}$ test was applied to the $2^{-\Delta \Delta \mathrm{Ct}}$ differential expression value at 0.01 significance level.

\subsection{Sequence Alignment and Molecular Modeling}

Protein sequences were retrieved from the NCBI database and the alignments were performed using the Clustal Omega software.

The molecular model predictions were obtained with i-Tasser. The structures were taken from Protein Data Bank (PDB) and the final comparative analysis was performed using PyMol program.

\section{Results}

\subsection{Primary Structure of LiUBC1}

The comparative analysis of the LiUBC1 sequence (encoded by the LinJ.33.2910 gene) with several ortholog proteins showed high identity (>80\%) within the genus Leishmania, including L. braziliensis, a species from the Viannia subgenus. The UBC1 from Trypanosoma cruzi is evolutionarily more distant, as $50 \%$ sequence identity was observed. The similarity with mammalian orthologs is lower, with values ranging between $30 \%$ and $40 \%$ in the human, hamster, and rabbit orthologs. Arabidopsis thaliana showed an amino acid identity value in the same range as mammalians (Figure 1, Table 1)

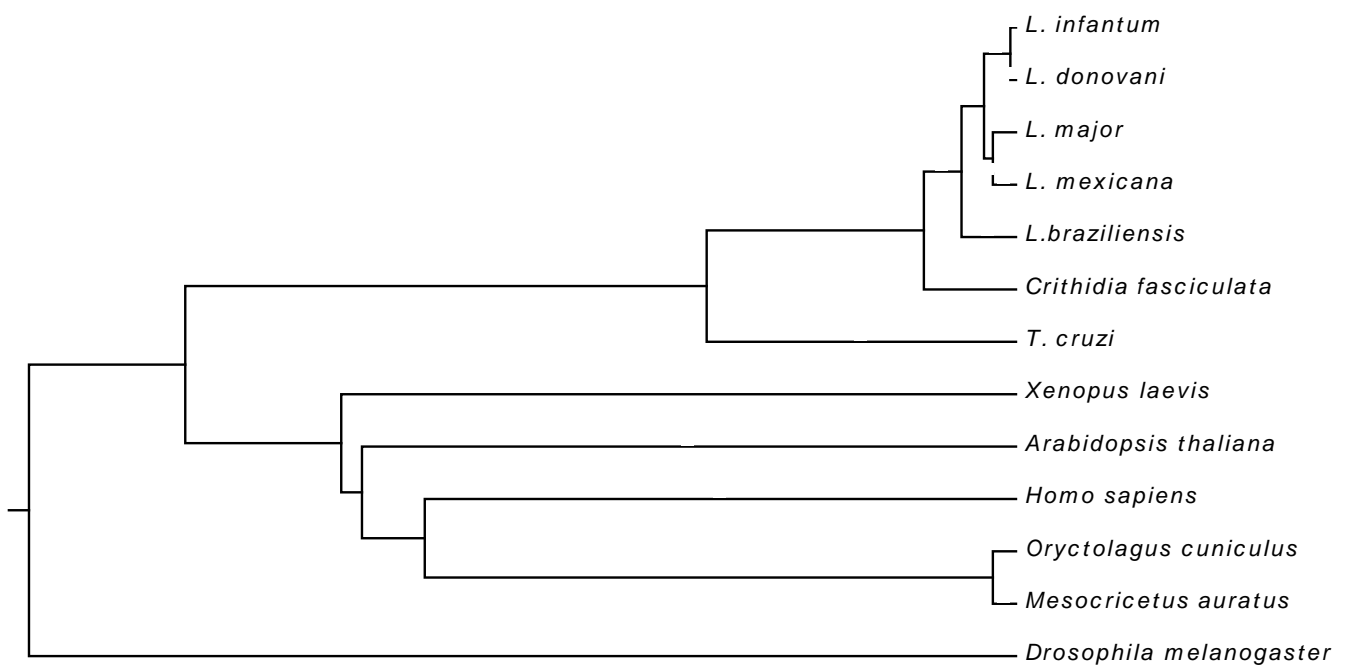

Figure 1. Phylogenetic analysis of the LiUBC1 protein: the phylogenetic tree with different species of the trypanosomatid family and with other orthologs; trypanosomatid orthologs are evolutionarily close, while mammalian orthologs are more distant.

Table 1. Percentages of identity between different LiUBC1 orthologs.

\begin{tabular}{cc}
\hline Species & \% Identity \\
\hline Leishmania donovani & 100 \\
Leishmania major & 100 \\
Leishmania mexicana & 91.70 \\
Leishmania braziliensis & 80.50 \\
Trypanosoma cruzi & 48.98 \\
Oryctolagus cuniculus & 38.09 \\
Homo sapiens & 31.30 \\
Xenopus laevis & 31.30 \\
Arabidopsis thaliana & 30.82 \\
Drosophila melanogaster & 27.14 \\
Mesocricetus auratus & 20.17
\end{tabular}


The results indicated a high level of LiUBC1 conservation within the genus, in both the Leishmania and Viannia subgenera. Identity decreases to $~ 50 \%$ within the Trypanosoma genus and further in the higher eukaryotes, especially mammals. However, the role of the LiUBC1 orthologs is presumably maintained, because the N-terminal domain is the most conserved region between these species (Figure S1). Taking into account that percentages of identity only provide partial information about the tertiary or quaternary structure of the proteins, as well as about the final functional performance of the proteins, we determined the predicted structure of the enzyme based on known structures.

\subsection{Molecular Models of LiUBC1}

We predicted the LiUBC1 model with solved structures of orthologs from Homo sapiens (1ZDN) [54] and S. cerevisiae (1TTE) [55], retrieved from PDB.

The predicted LiUBC1 structure is composed of a C-terminal domain and a UBC catalytic core. This structure is similar to the structure of the S. cerevisiae E2 ubiquitinconjugating enzyme (Figure 2B), which has been described as one homodimer [53]. The human ortholog enzyme lacks the C-terminal domain (Figure 2C) present in LiUBC1 and S. cerevisiae proteins, but the N-terminal end, which contains the enzyme's active center, also displays a very similar structure (Figure 2D).

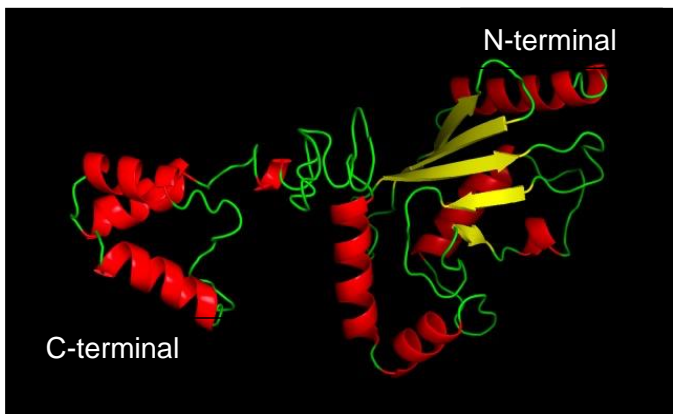

(a)

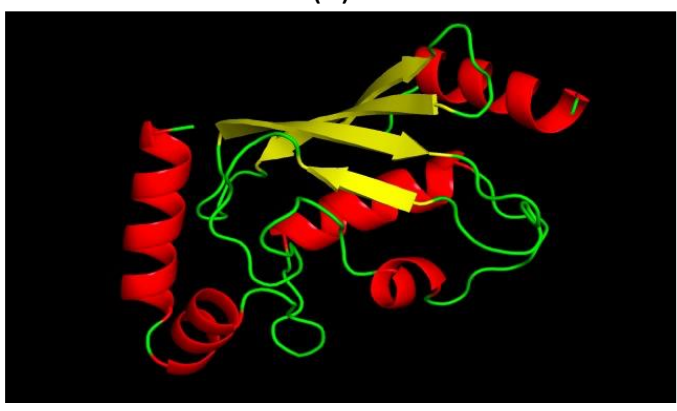

(c)

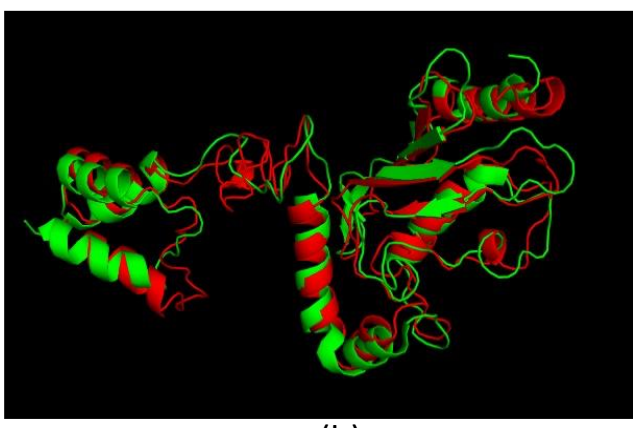

(b)

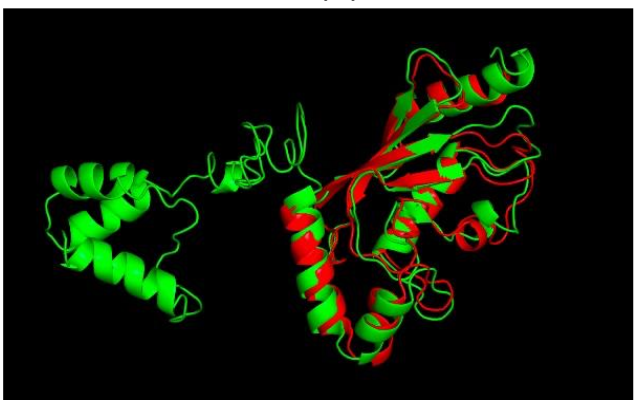

(d)

Figure 2. Structure modeling of LiUBC1 compared with resolved structures of homologous proteins: (a) LiUBC1 structure model indicating the C-and $\mathrm{N}$-termini ( $\alpha$-helixes in red, $\beta$-sheets in yellow, random coil in green); (b) comparison of LiUBC1 (red) with the ortholog protein from $S$. cerevisiae (green) ScUBC1; (c) structure of the H. sapiens ortholog protein (HsUBC1) ( $\alpha$-helixes in red, $\beta$-sheets in yellow, random coil in green); (d) comparison of LiUBC1 (green) and HsUBC1 (red).

\subsection{LiUBC1 Purification}

The LinJ.33.2910 gene, which encodes LiUBC1, was cloned in the pQE30 expression vector in the E. coli XL1-blue strain, and the M15 strain for LiUBC1 overexpression in a heterologous system. LiUBC1 was expressed in the presence of $1 \mathrm{mM}$ IPTG at an optimal temperature of $37^{\circ} \mathrm{C}$ (Figure 3A). Most of the overexpressed protein was located in the nonsoluble fraction (Figure 3B). The LiUBC1 protein was solubilized with a buffer containing $5 \mathrm{M} \mathrm{GuHCl}$ and $40 \mathrm{mM}$ imidazole and purified in batch using a $\mathrm{Ni}^{2+}-\mathrm{NTA}^{2}$ agarose column. Discontinuous elution was performed in three steps using 100, 400, and 
$700 \mathrm{mM}$ imidazole, respectively. Most of the LiUBC1 protein was eluted at an imidazole concentration of $700 \mathrm{mM}$. The purified protein presented a complex pattern with bands that may correspond to the molecular weights of the LiUBC1 protein $(26 \mathrm{kDa}$ plus the histidine tag), as well as bands that may correspond to aggregates (Figure 3C).

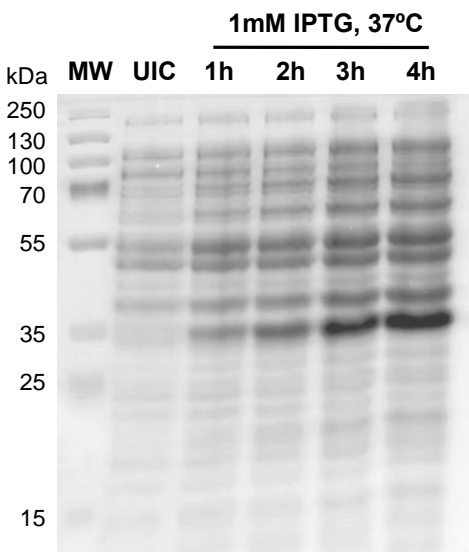

(a)

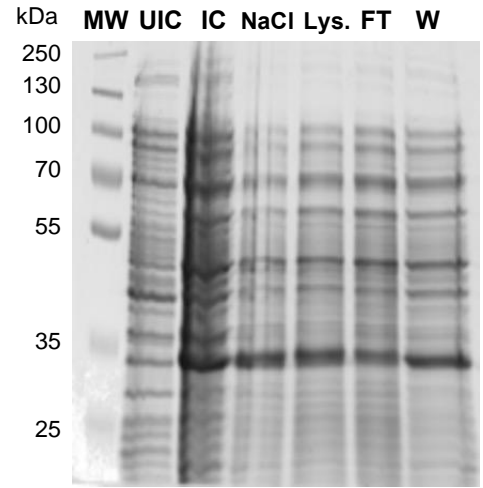

(b)

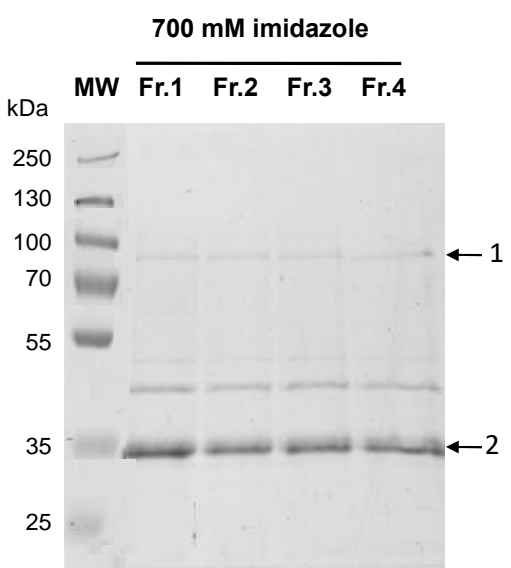

(c)

Figure 3. LiUBC1 expression and purification: (a) LiUBC1 protein expression detection by SDSPAGE in the presence of $1 \mathrm{mM} \mathrm{IPTG}$, induction from 1 to $4 \mathrm{~h}$ at $37^{\circ} \mathrm{C}$; (b) UIC-uninduced culture, IC —induced culture, $\mathrm{NaCl}-\mathrm{NaCl}$ wash, Lys.—Lysate, FT—flow through, W—wash with $200 \mathrm{mM}$ imidazole; (c) LiUBC1 eluted in $700 \mathrm{mM}$ imidazole. Arrows indicate the LiUBC1 protein and possible aggregates.

To confirm the presence of LiUBC1 aggregates, the bands were excised, in-gel SDSPAGE trypsin-digested, and analyzed by nLC-MS/MS (Table 2).

Table 2. LiUBC1 protein band identification by nLC-MS/MS. The protein bands were excised from Table 3. C. Proteins were extracted from the gel and analyzed by nLC-MS/MS. The MASCOT score is a statistical parameter that indicates that the identification is reliable $(p<0.05)$ when values are higher than 52. The coverage indicates the percentage of the protein sequence which has been detected in each case.

\begin{tabular}{c|cccc}
\hline \multicolumn{1}{c}{ BAND } & Gene & Description & Score & Coverage \\
\hline $\mathbf{1}$ & LinJ.33.2910 & Ubiquitin-conjugating enzyme E2 & 1235 & 91.70 \\
$\mathbf{2}$ & LinJ.33.2910 & Ubiquitin-conjugating enzyme E2 & 487 & 70.54 \\
\hline
\end{tabular}

The two bands correspond to the LiUBC1, confirming the obtainment of the purified recombinant enzyme, and suggest the presence of the protein in bands corresponding to aggregates that could be dimers. The presence of faint bands with intermediate molecular weights may also indicate the existence of intermediate forms, probably due to the sensitivity of LiUBC1 to degradation agents even in the presence of protease inhibitors.

\subsection{LiUBC1 Expression Levels throughout the Growth Curve of IPER/ES/2013/ATE1FL6 Strain of} L. infantum Promastigotes in Axenic Culture

We studied the expression of LiUBC1 in the highly infective IPER/ES/2013/ATE1FL6 strain obtained from $P$. perniciosus gut during a human outbreak of the disease in Spain (Section 2.1). Figure 4 shows the growth curve, as well as the expression of the LiUBC1 protein. The strain from the human outbreak (Figure 4A) has a lag phase that extends to day three, followed by a sharp logarithmic phase that reaches a maximum at day 6 and a short stationary phase before the rapid start of cell death on day 7 . 


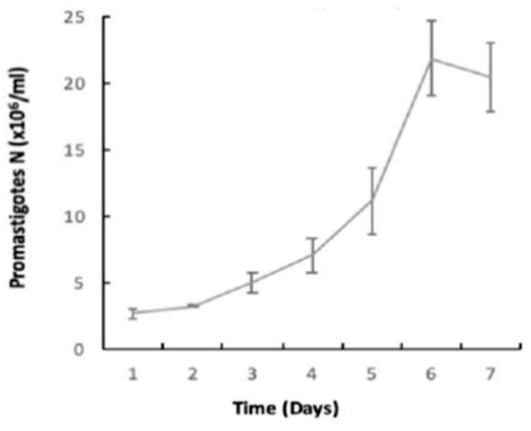

(a)

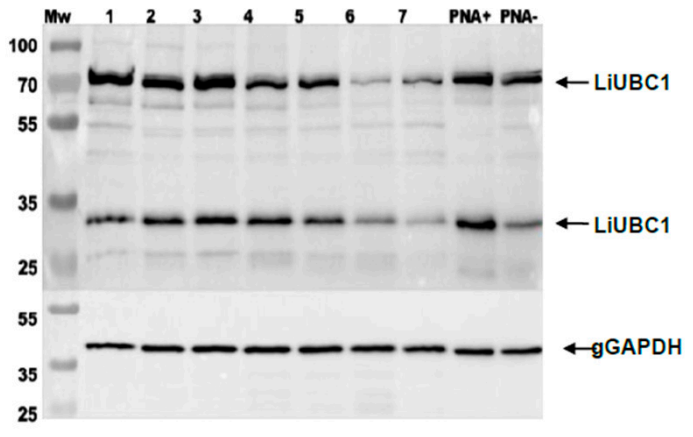

(b)

Figure 4. LiUBC1 expression patterns: (a) growth curve of the human outbreak strain (IPER/ES/2013/ATE1FL6); (b) Western blot analysis of the LiUBC1 protein extracted from parasite samples taken during the different days of growth of the human outbreak strain and the samples obtained with the PNA selection. Arrows indicate the possible weight corresponding to the monomer $(\sim 35 \mathrm{kDa})$ and dimer $(\sim 70 \mathrm{kDa})$ bands of the protein. All densitometry data of each band can be seen at Supplementary Materials file (Figure S2).

The Western blot analysis of the extracts obtained from each day of culture also showed the different protein expression patterns of LiUBC1. The strain from the human outbreak displayed two bands that may correspond to the monomer and dimer forms of the enzyme, with a slight decrease at the stationary phase of growth as indicated by the gGADPH controls, as well as the presence of faint intermediate forms.

The LiUBC1 expression pattern was similar in the PNA selection extracts, though there was a lower expression of the monomeric form in the PNA extracts.

\subsection{Subcellular Localization of LiUBC1 in the L. infantum Parasite}

IIF experiments with the anti-LiUBC1 polyclonal antibody displayed a particulate distribution of the protein in two parasite areas: the nucleus and the kinetoplast area (Figure 5). This technique did not allow us to differentiate between the nuclear membrane and the perinuclear cytoplasmic zone. The same happened with the presence of the protein in the flagellar pocket area. To clarify this point, we carried out TEM experiments.

TEM using the same LiUBC1 primary antibody and the antirabbit IgG conjugated to colloidal gold was carried out to obtain more accurate information about the LiUBC1 subcellular localization. This experiment revealed that the protein is located in the nuclear envelope area, as well as in the kinetoplast and adjacent to the flagellar pocket membrane (Figure 6). 
Preimmune

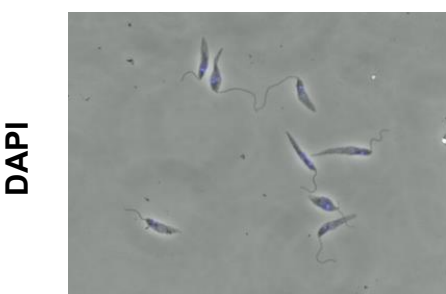

(a)

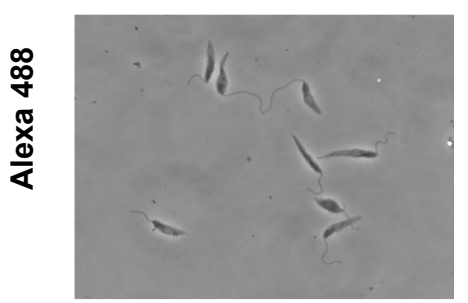

(b) $\alpha \operatorname{\alpha iUBC1}$

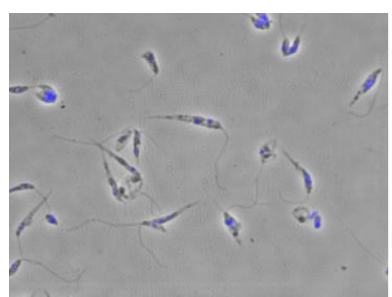

(c)

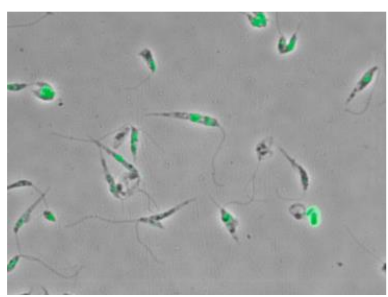

(d)

Figure 5. Indirect immunofluorescence of L. infantum (IPER/2013/ATE1FL6) promastigotes. The rabbit preimmune serum $(\mathbf{a}, \mathbf{b})$ and the anti-LiUBC1 polyclonal antibody $(\mathbf{c}, \mathbf{d})$ were used. The secondary antibody was the goat antirabbit IgG conjugated to Alexa Fluor 488. As can be seen in the figure, the LiUBC1 protein is localized in the nucleus and the kinetoplast area (green fluorescence from Alexa Fluor $488(\mathbf{b}, \mathbf{d})$ colocalized with DAPI $(\mathbf{a}, \mathbf{c})$ in blue).

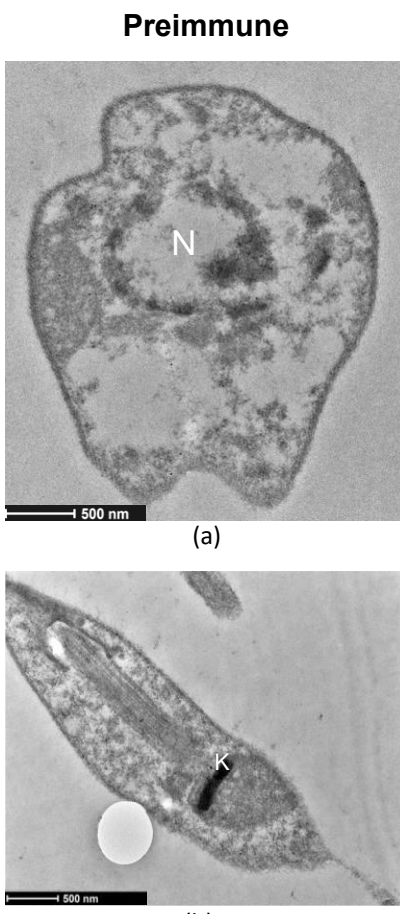

(b)

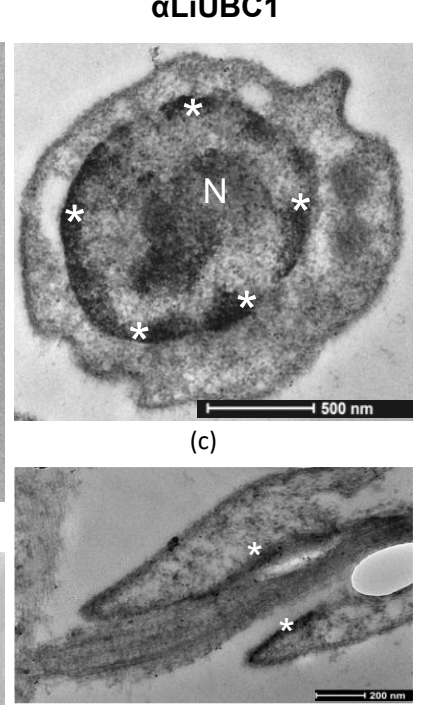

(d)

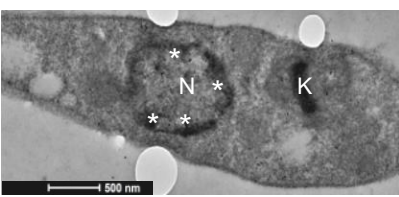

(e)

Figure 6. Immunolocalization of LiUBC1 using TEM. Asterisks $\left(^{*}\right)$ indicate the presence of gold precipitate corresponding to the presence of LiUBC1 protein in the different parasite subcellular structures. (a) Transverse section of L. infantum promastigotes incubated with preimmnune antibody. (b) L. infantum promastigotes incubated with preimmnune antibody. (c) Transverse section of $L$. infantum cell incubated with anti-LiUBC1 antibody. (d) Detail of the flagellar pocket area incubated with specific anti-LiUBC1 antibody. (e) Detail of the parasite's nucleus incubated with specific serum anti-LiUBC1 antibody. $\mathrm{N}$-nucleus; $\mathrm{K}$-kinetoplast. 
The TEM experiments confirmed the presence of LiUBC1 in the nuclear membrane area, as well as the flagellar pocket and the kinetoplast.

\subsection{Characterization of an L. infantum Stable LiUBC1 Knock-In Promastigote Cell Line}

A knock-in cell line was generated for functional studies using the infective human outbreak strain (Section 2.1). Figure 7A shows the growth pattern of L. infantum parasites overexpressing LiUBC1. Both growth curves, corresponding to the pIRmcs3-LiUBC1and the pIRmcs3-transfected promastigotes, show similar patterns. The expression levels of the LiUBC1 protein are similar throughout the growth curve in the case of the pIRmcs3-transfected promastigotes (Figure 7B). The transfected promastigotes overexpressing LiUBC1 showed a higher expression of LiUBC1 at the beginning of the growth curve, mostly in the first $24 \mathrm{~h}$ (Figure 7C).

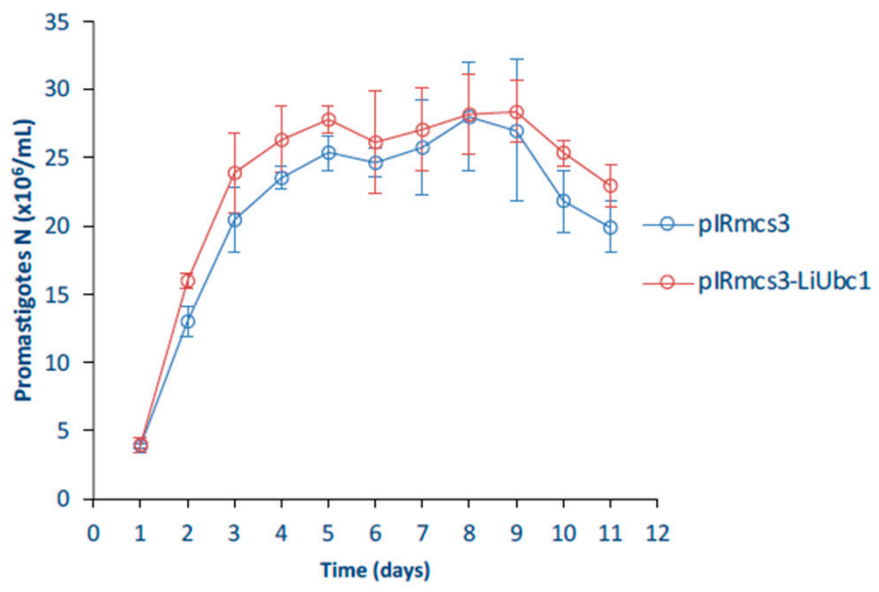

(a)

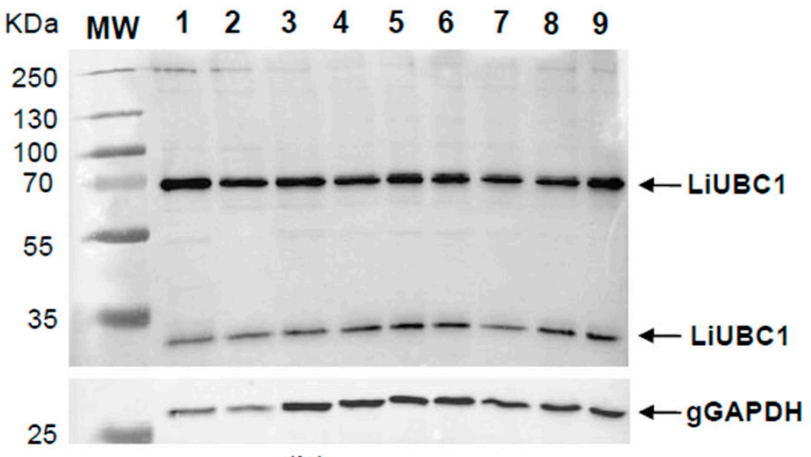

(b)

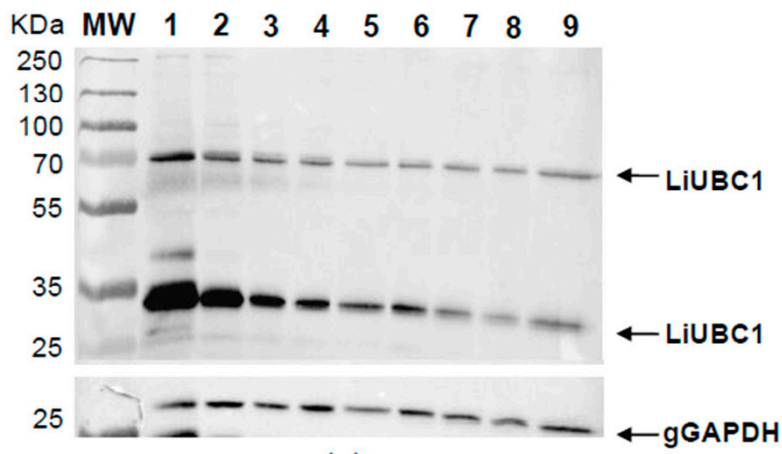

(c)

Figure 7. Growth and LiUBC1 levels in the pIRmcs3-LiUBC1 knock-in L. infantum promastigote cell line: (a) growth curve of the transfected L. infantum strain, transfectants containing the pIRmcs 3 vector in blue and pIRmcs3-LiUBC1 knock-in cell line in red; (b) Western blot pattern of the LiUBC1 protein throughout growth of pIRmcs3 control transfectants; (c) pIRmcs3-LiUBC1 knock-in promastigotes.

We validated the results shown in Figure 7 using iTRAQ. We analyzed the proteome pattern of the transfected parasite and the possible modifications induced by this noticeable increase in the ubiquitin-conjugating E2 enzyme on other related enzymes of the ubiquitin-conjugating system. Thus, we used the following ubiquitin enzymes (putative) as a reference: the E1-activating E1 enzyme, the ubiquitin-conjugating E2 enzyme, and the ubiquitin-conjugating E3 enzyme, corresponding to the LinJ.23.0710, LinJ.35.1310, and LinJ.13.1320 genes, respectively. Table 3 shows the levels of the relative abundance of these proteins with respect to LiUBC1. The overexpression of LiUBC1 does not affect the pro- 
duction of these similar conjugating and activating enzymes. Thus, proteins belonging to the ubiquitin proteasome system are not generally overexpressed, while those of ubiquitin modification systems are, specifically, LiUBC1.

Table 3. Results of the LC-MS/MS analysis (iTRAQ). The expression levels of the LiUBC1 protein and those of other genes related to the ubiquitins of L. infantum are shown. The minimum level of relative abundance was set at a ratio of $2(\log 2$ ratio $\geq 1)$.

\begin{tabular}{lcccc}
\hline \multirow{2}{*}{ Gene } & Description & \multicolumn{2}{c}{ Mean pIRmcs3-LiUBC1 vs. pIRmcs3 } \\
\cline { 2 - 4 } & & Day 1 & Day 3 & Day 5 \\
\hline LinJ.33.2910 & $\begin{array}{c}\text { LiUBC1 } \\
\text { Ubiquitin-conjugating enzyme } \\
\text { E2, putative }\end{array}$ & $2.759 \pm 0.30$ & $0.031 \pm 0.11$ & $0.327 \pm 0.51$ \\
\hline LinJ.23.0710 & $\begin{array}{c}\text { Ubiquitin-conjugating enzyme } \\
\text { E1, putative }\end{array}$ & $0.008 \pm 0.01$ & $0.062 \pm 0.07$ & $0.083 \pm 0.06$ \\
\hline LinJ.35.1310 & $\begin{array}{c}\text { Ubiquitin-conjugating enzyme } \\
\text { E2, putative }\end{array}$ & $0.021 \pm 0.01$ & $0.095 \pm 0.14$ & $0.264 \pm 0.25$ \\
\hline LinJ.13.1320 & $\begin{array}{c}\text { Ubiquitin-conjugating enzyme, } \\
\text { putative }\end{array}$ & $0.225 \pm 0.29$ & $0.317 \pm 0,40$ & $0.087 \pm 0.59$ \\
\hline
\end{tabular}

\subsection{Infectivity of LiUBC1 Knock-In Promastigotes in U937 Cells In Vitro}

In vitro infection experiments were performed using the PMA stimulated U937 cell line model. Figure 8 shows the percentage of U937 cells infected by L. infantum LiUBC1 knock-in promastigotes (red bars) and pIRmcs3 transfected promastigotes (blue bars). Slight differences are observed (Figure 8A). A statistically significant ( $t$-test, $p<0.05$ ) 27\% average increase in the number of amastigotes per infected cell was observed in the $24 \mathrm{~h}$ post-infection timeframe (Figure 8B), i.e., early infection stage.

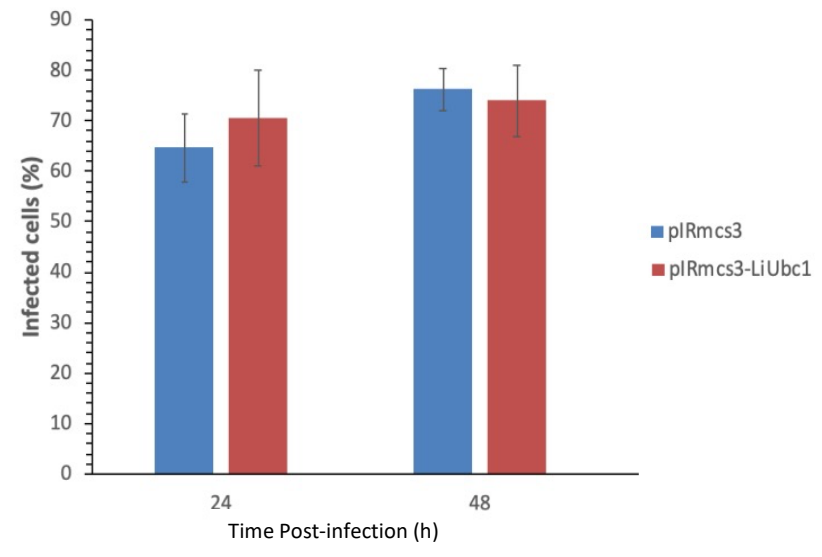

(a)

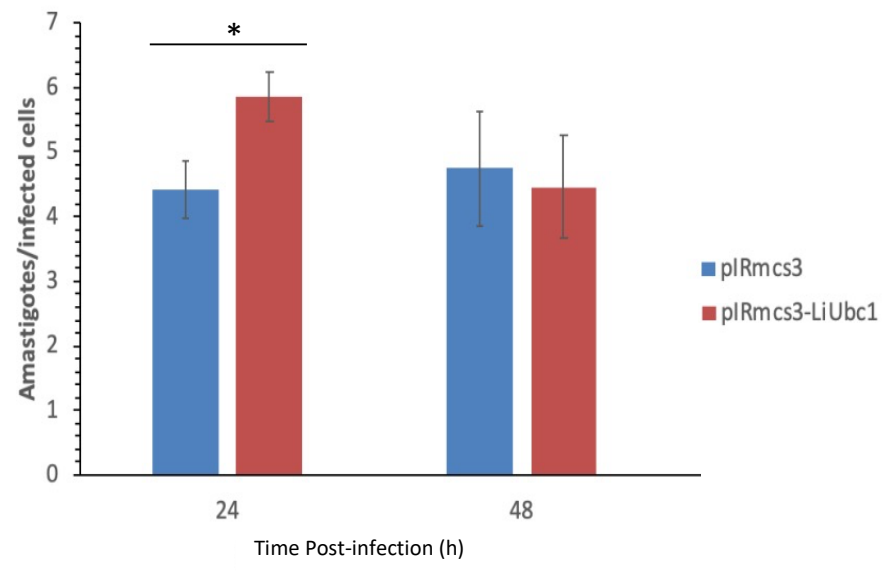

(b)

Figure 8. In vitro infection of U937 myelomonocytic cells with transfected L. infantum parasites: (a) percentage of infected phagocytes at 24 and $48 \mathrm{~h}$ post-infection; (b) number of amastigotes per infected cell at 24 and $48 \mathrm{~h}$ post-infection. Blue bars: infection with parasites transfected with empty plasmid. Red bars: U937 cells infected with the LiUBC1 overexpressing plasmid. *Statistical inference was performed using the Student's t-test * $p<0.05$.

An increase of the presence of intracellular amastigotes in U937 cells infected with promastigotes overexpressing the LiUBC1 gene in the early phases (Figure 8) suggests a probable role of LiUBC1 in the parasite infection process. 
3.8. Protective Effect of the LiUBC1 Recombinant Protein in M. auratus against L. infantum Challenge

The possible role of the LiUBC1 recombinant protein as a protective molecule against L. infantum infection was evaluated herein. The investigation was performed using the $M$. auratus model in a challenge experiment with $L$. infantum promastigotes. Four months post-infection, $50 \%$ of the control animals showed the presence of L. infantum amastigotes in the spleen, whereas animals vaccinated with the recombinant LiUBC1 protein did not (Table 4).

Additionally, we analyzed the IgG anti-SLA and IFN- $\gamma$ production. As can be seen in Figure 9A, the production of IgG anti-SLA was increased in the animals inoculated with LiUBC1 recombinant protein. Additionally, the IFN- $\gamma$ production in the spleen cells of the animals inoculated with the recombinant protein showed a statistically significant increase (Figure 9B).

Table 4. Evaluation of the parasite load by limiting dilution in the protection experiment against L. infantum infection of hamsters inoculated with the LiUBC1 recombinant protein. Four technical replicates of serial dilutions were made. The geometric mean of the dilution limit $\left(\mathrm{M}_{\mathrm{G}}\right)$ was used to calculate the number of amastigotes per gram of tissue.

\begin{tabular}{ccccc}
\hline Group & Sample $^{\mathbf{0}}$ & Spleen Weight $(\mathbf{g})$ & $\mathbf{M}_{\mathbf{G}}$ Dilution Limit & Amas/g Spleen \\
\hline & 1 & 0.1123 & - & - \\
& 2 & 0.1099 & - & - \\
LiUBC1 & 3 & 0.0844 & - & - \\
& 4 & 0.1236 & - & - \\
& 5 & 0.1025 & - & - \\
& 6 & 0.0844 & - & - \\
& 7 & 0.0925 & - & - \\
& 8 & 0.1299 & - & 2469 \\
& 9 & 0.1371 & 16 & - \\
& 10 & 0.0972 & - & 6382 \\
& 11 & 0.1161 & - & 22094 \\
\hline
\end{tabular}

Ig G anti-S LA

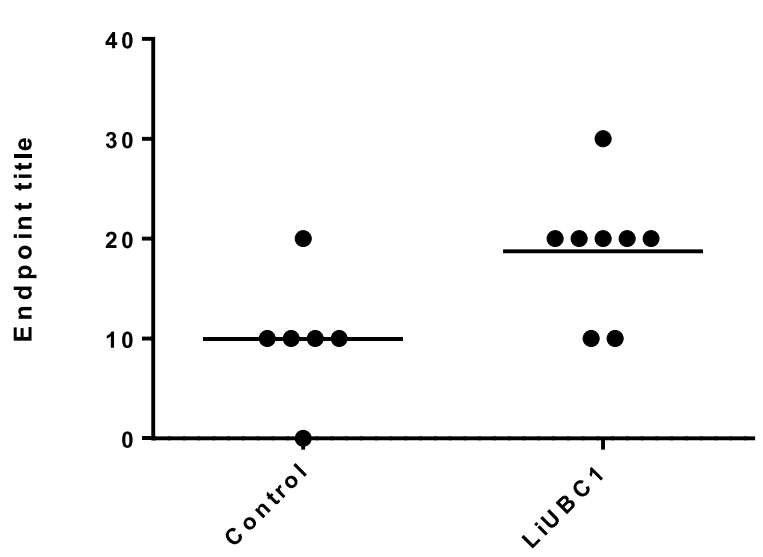

(a)
IFN- $\gamma$

spleen

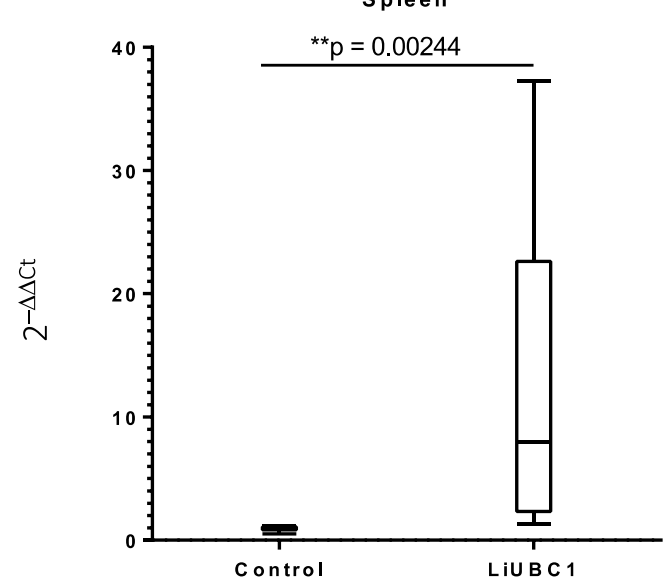

(b)

Figure 9. Evaluation of the specific immune response in $M$. auratus: (a) humoral immunity (IgG antiSLA); (b) cellular immunity. We used qPCR for the quantification of the relative IFN- $\gamma$ mRNA levels in splenocytes (IFN- $\gamma)$. Statistical inference was performed using the Student's t-test $\left({ }^{* *} p<0.01\right)$. 
The results of the parasite burden, the IgG anti-SLA, and the IFN- $\gamma$ production suggest the possible role of the LiUBC1 recombinant protein as a protective molecule against $L$. infantum infection.

\section{Discussion}

LiUBC1 is a protein involved in degradation and regulation mechanisms essential for the adaptation of the cell to distinct physiological conditions, helping to maintain cell homeostasis. Processes such as DNA repair or protein synthesis are regulated by ubiquitin [34]. This may be relevant for Leishmania parasites, which have to adapt to the different environments along its life cycle in two different hosts, from the vector gut to the macrophage parasitophorous vacuole. We characterized the protein in a lower eukaryote, and it displays structural features similar to other members of the Leishmania genus and other lower eukaryotes, such as S. cerevisiae, but dissimilar to other members of the Trypanosomatidae family. The protein structure of LiUBC1, predicted based on the data obtained from S. cerevisiae and H. sapiens orthologs, showed a C-terminal end very similar to that observed in the yeast protein, which is not present in the human enzyme (Figure 2). This fact suggests that the LiUBC1 enzyme may be a good vaccine or drug target candidate, whose blockage through the C-terminus would only affect the parasite's survival and not their host, providing a good pharmacological advantage for a possible treatment for humans infected with L. infantum. This increases the interest in unraveling the characterization of LiUBC1 from L. infantum, responsible for VL in the Mediterranean basin, China, and South America.

The purified recombinant LiUBC1 protein displayed a complex pattern with the presence of two main bands (Figure 3) that showed molecular weights corresponding to the monomer and the dimer, as confirmed by LC-MS/MS (Table 2). A specific antibody was obtained to study the LiUBC1 expression pattern and subcellular localization throughout the promastigote growth curve.

The immunofluorescence experiments showed localization in the nuclear area and close to the base of the parasite's flagellum. TEM analysis confirmed the presence of LiUBC1 in the nuclear membrane zone, as well as the kinetoplast and the flagellar pocket area. This localization corresponds to the assigned functions of the protein. The protein is only located near protein-synthesis and -modification areas, and not throughout the entire cytoplasm, in a parasite in which autophagy and endosome sorting are essential in metacyclogenesis [56]. In Leishmania, the perinuclear zone has been shown to control post-translational regulation [57], which would require the presence of ubiquitin activity. The internalization of exogenous polypeptides and proteins through the flagellar pocket (cytostome) may be related to ubiquitin targeting for degradation [37]. The generation of knock-in transfectants helps us study the possible relation of the ubiquitin-conjugating E2 protein with the parasite's infectivity. LiUBC1-transfected promastigotes showed a clear predominance of the monomer form over the aggregate. The LiUBC1 knock-in promastigote line reached the highest levels of protein expression at the beginning of the growth curve (Figure 7). This high amount of the monomeric form rapidly decayed at 72 $\mathrm{h}$, reaching normal levels. The iTRAQ-based proteome analysis of the LiUBC1 knock-in promastigotes revealed that $\mathrm{LiUBC1}$ overexpression did not affect the intracellular levels of any other identified protein. Overexpression was confirmed in the pIRmcs3-LiUBC1 stable knock-in promastigote cell line. Growth and morphology were not altered in this cell line and, according to iTRAQ analysis, constitutively induced LiUBC1 expression did not lead to pleiotropic effects consisting of substantial changes in the proteome. The cell line overexpressing the LiUBC1 gene was more infective to PMA-stimulated U937 cells during the $24 \mathrm{~h}$ post-infection, as seen by the increase in intracellular amastigotes in the infected cells. The increase in infectivity at an early stage induced by LiUBC1 gene overexpression (Figure 8) suggests that immunization with this molecule may protect the host against infection. A protection experiment against a challenge with L. infantum in the M. auratus model was performed. In this experiment, the humoral and cellular immune response 
against the parasite was increased in the vaccinated animals. Furthermore, inoculation with the protein elicited a moderate, although clear, protection against parasite infection. These results agree with those obtained using a closely related E2 enzyme from L. donovani, which showed its ability to protect against infection in the mouse model [58]. Recent data indicate the presence of specific antibodies against the E2 protein in human serum obtained from VL patients [59].

Taken as a whole, these results are encouraging and indicate that further studies should be carried out on the role of the ubiquitin-conjugating E2 enzyme in the key functions of $L$. infantum metabolism, especially in the regulation processes. The unraveling of the role of the enzyme as a response to the parasite's environmental conditions along its biological cycle would provide basic knowledge on the regulation mechanisms of this protozoa. This knowledge would also be useful for the development of effective drugs or vaccines against the parasite.

\section{Conclusions}

LiUBC1 is similar ( $>80 \%$ ) to orthologs from the Leishmania spp., but not to the mammalian orthologs included in the comparison $(<40 \%)$, which lack the C-terminal domain found in Leishmania spp. According to the Western blot experiment, the LiUBC1 gene is expressed throughout L. infantum promastigote growth, including highly infective PNApromastigotes. The Syrian hamster protection experiment against challenge with L. infantum revealed a partial reduction in parasite burden and IFN- $\gamma$ mRNA levels in the spleen. Therefore, LiUBC1 is a vaccine candidate that confers partial protection in Syrian hamsters against $L$. infantum infection.

Supplementary Materials: The following supporting information can be downloaded at: https: / / www.mdpi.com/article/10.3390/vaccines10020231/s1, Figure S1: Comparative alignment of the primary structure of the LiUBC1 protein, Figure S2: Raw Western Blot Images.

Author Contributions: Conceptualization, P.J.A., A.A. and V.L.; methodology, P.J.A., A.A., L.T.C.M., I.M., M.D. and J.L.; formal analysis, P.J.A., A.A., I.M. and J.L.; investigation, J.L.; resources M.D. and V.L.; writing—original draft preparation, V.L., P.J.A. and J.L.; writing—review and editing, V.L., A.A., P.J.A. and J.L.; visualization, I.M. and J.L.; supervision, P.J.A., A.A. and V.L.; project administration, V.L.; funding acquisition, P.J.A. and V.L. All authors have read and agreed to the published version of the manuscript.

Funding: This work was financed by a contract with CZ Vaccines, Porriño, Spain, and partially defrayed by a grant from the Fundación Ramón Areces. JL thanks CZ Vaccines for the fellowship.

Institutional Review Board Statement: The study was conducted according to the guidelines of the Declaration of Helsinki, and approved by the Instituto de Salud Carlos III Ethical Advisory Committee for Animal Experimentation following the UE Directive 2010/63 and the Spanish regulation RD53/2013, and the Consejo Superior de Investigaciones Científicas (CSIC) Ethical Committee (EU Directive 2010/63 and Spanish regulation RD53/2013).

Informed Consent Statement: Not applicable.

Data Availability Statement: All data are included in the manuscript and the supplementary files.

Acknowledgments: We want to thank Francisco J. Loayza for editing the manuscript. We also want to give thanks for the help provided by Esperanza Pérez Pastrana with the TEM experiment. This work was financed by a contract with CZ Vaccines (Porriño, Pontevedra, Spain), as well as partially defrayed by a grant from the Fundación Ramón Areces (2018-2020). JL thanks CZ Vaccines for the fellowship.

Conflicts of Interest: The authors declare no conflict of interest. The funders had no role in the design of the study; in the collection, analyses, or interpretation of data; in the writing of the manuscript, or in the decision to publish the results. 


\section{References}

1. OMS. Report of a Meeting of the WHO Expert Committee on the Control of Leishmaniases; World Health Organization: Geneva, Switzerland, 2010.

2. Alvar, J.; Canavate, C.; Gutierrez-Solar, B.; Jimenez, M.; Laguna, F.; Lopez-Velez, R.; Molina, R.; Moreno, J. Leishmania and human immunodeficiency virus coinfection: The first 10 years. Clin. Microbiol. Rev. 1997, 10, 298-319. [CrossRef] [PubMed]

3. Desjeux, P. Leishmania/HIV co-infections. Afr. Health 1995, 18, 20-22. [PubMed]

4. Desjeux, P.; Piot, B.; O'Neill, K.; Meert, J.P. Co-infections of leishmania/HIV in south Europe. Med. Trop. Rev. Corps Sante Colon. 2001, 61, 187-193.

5. Jiménez, M.; Alvar, J.; Tibayrenc, M. Leishmania infantum is clonal in AIDS patients too: Epidemiological implications. AIDS 1997, 11,569-573. [CrossRef] [PubMed]

6. Wolday, D.; Berhe, N.; Akuffo, H.; Desjeux, P.; Britton, S. Emerging Leishmania/HIV co-infection in Africa. Med. Microbiol. Immunol. 2001, 190, 65-67. [CrossRef] [PubMed]

7. Desjeux, P. Leishmaniasis: Public health aspects and control. Clin. Dermatol. 1996, 14, 417-423. [CrossRef]

8. Mauricio, I.L.; Stothard, J.R.; Miles, M.A. The Strange Case of Leishmania chagasi. Parasitol. Today 2000, 16, 188-189. [CrossRef]

9. Arce, A.; Estirado, A.; Ordobas, M.; Sevilla, S.; García, N.; Moratilla, L.; De La Fuente, S.; Martínez, A.M.; Pérez, A.M.; Aránguez, E.; et al. Re-emergence of leishmaniasis in Spain: Community outbreak in Madrid, Spain, 2009 to 2012. Eurosurveillance 2013, 18, 20546. [CrossRef]

10. Jiménez, M.; González, E.; Martin-Martin, I.; Hernández, S.; Molina, R. Could wild rabbits (Oryctolagus cuniculus) be reservoirs for Leishmania infantum in the focus of Madrid, Spain? Veter Parasitol. 2014, 202, 296-300. [CrossRef]

11. Martin-Martin, I.; Molina, R.; Rohousova, I.; Drahota, J.; Volf, P.; Jiménez, M. High levels of anti-Phlebotomus perniciosus saliva antibodies in different vertebrate hosts from the re-emerging leishmaniosis focus in Madrid, Spain. Veter. Parasitol. 2014, 202, 207-216. [CrossRef]

12. Molina, R.; Jiménez, M.I.; Cruz, I.; Iriso, A. The hare (Lepus granatensis) as potential sylvatic reservoir of Leishmania infantum in Spain. Vet. Parasitol. 2012, 190, 268-271. [CrossRef] [PubMed]

13. Abranches, P.; Silva-Pereira, M.C.D.; Conceicao-Silva, F.M.; Santos-Gomes, G.M.; Janz, J.G. Canine Leishmaniasis: Pathological and Ecological Factors Influencing Transmission of Infection. J. Parasitol. 1991, 77, 557-561. [CrossRef] [PubMed]

14. Semião-Santos, S.J.; El Harith, A.; Ferreira, E.; Pires, C.A.; Sousa, C.; Gusmão, R. Evora district as a new focus for canine leishmaniasis in Portugal. Parasitol. Res. 1995, 81, 235-239. [PubMed]

15. Moody, S.F. Molecular variation in Leishmania. Acta Trop. 1993, 53, 185-204. [CrossRef]

16. Sundar, S.; Rai, M. Advances in the treatment of leishmaniasis. Curr. Opin. Infect. Dis. 2002, 15, 593-598. [CrossRef]

17. Singh, N.; Kumar, M.; Singh, R.K. Leishmaniasis: Current status of available drugs and new potential drug targets. Asian Pac. J. Trop. Med. 2012, 5, 485-497. [CrossRef]

18. Cotrina, J.F.; Iniesta, V.; Monroy, I.; Baz, V.; Hugnet, C.; Marañon, F.; Fabra, M.; Gómez-Nieto, L.C.; Alonso, C. A large-scale field randomized trial demonstrates safety and efficacy of the vaccine LetiFend(R) against canine leishmaniosis. Vaccine 2018, 36, 1972-1982. [CrossRef]

19. Oliva, G.; Nieto, J.; Manzillo, V.F.; Cappiello, S.; Fiorentino, E.; Di Muccio, T.; Scalone, A.; Moreno, J.; Chicharro, C.; Carrillo, E.; et al. A Randomised, Double-Blind, Controlled Efficacy Trial of the LiESP/QA-21 Vaccine in Naïve Dogs Exposed to Two Leishmania infantum Transmission Seasons. PLOS Negl. Trop. Dis. 2014, 8, e3213. [CrossRef]

20. Borja-Cabrera, G.P.; Mendes, A.C.; de Souza, E.P.; Okada, L.Y.H.; de A Trivellato, F.A.; Kawasaki, J.K.A.; Costa, A.C.; Reis, A.B.; Genaro, O.; Batista, L.M.M.; et al. Effective immunotherapy against canine visceral leishmaniasis with the FML-vaccine. Vaccine 2004, 22, 2234-2243. [CrossRef]

21. Palatnik-De-Sousa, C.B. Vaccines for Canine Leishmaniasis. Front. Immunol. 2012, 3, 69. [CrossRef]

22. Alcolea, P.J.; Alonso, A.; Larraga, V. The antibiotic resistance-free mammalian expression plasmid vector pPAL for development of third generation vaccines. Plasmid 2018, 101, 35-42. [CrossRef] [PubMed]

23. Gifawesen, C.; Farrell, J.P. Comparison of T-cell responses in self-limiting versus progressive visceral Leishmania donovani infections in golden hamsters. Infect. Immun. 1989, 57, 3091-3096. [CrossRef] [PubMed]

24. Vasconcellos, R.C.; Urago, K.P.; Bunn-Moreno, M.M.; Madeira, E.D. Suppressor activity in Leishmania donovani-infected hamster serum: Reversion by delipidated bovine serum albumin and role in cell cycle events. Braz. J. Med. Biol. Res. 1996, $29,615-622$. [PubMed]

25. Requena, J.M.; Soto, M.; Doria, M.D.; Alonso, C. Immune and clinical parameters associated with Leishmania infantum infection in the golden hamster model. Veter. Immunol. Immunopathol. 2000, 76, 269-281. [CrossRef]

26. Sacks, D.B.; Noben-Trauth, N. The immunology of susceptibility and resistance to Leishmania major in mice. Nat. Rev. Immunol. 2002, 2, 845-858. [CrossRef]

27. Alcolea, P.J.; Alonso, A.; Esteban, A.; Peris, P.; Cortés, A.; Castillo, J.A.; Larraga, V. IL12 p35 and p40 subunit genes administered as pPAL plasmid constructs do not improve protection of pPAL-LACK vaccine against canine leishmaniasis. PLoS ONE 2019, 14, e0212136. [CrossRef] [PubMed]

28. Leifso, K.; Cohen-Freue, G.; Dogra, N.; Murray, A.; McMaster, W.R. Genomic and proteomic expression analysis of Leishmania promastigote and amastigote life stages: The Leishmania genome is constitutively expressed. Mol. Biochem. Parasitol. 2007, 152, 35-46. [CrossRef] [PubMed] 
29. Alcolea, P.J.A.; Alonso, A.; Larraga, V. Proteome Profiling of Leishmania Infantum Promastigotes. J. Eukaryot. Microbiol. 2011, 58, 352-358. [CrossRef]

30. Rosenzweig, D.; Smith, D.; Myler, P.J.; Olafson, R.W.; Zilberstein, D. Post-translational modification of cellular proteins during Leishmania donovani differentiation. Proteomics 2008, 8, 1843-1850. [CrossRef]

31. Alcolea, P.J.; Alonso, A.; Molina, R.; Jiménez, M.; Myler, P.J.; Larraga, V. Functional genomics in sand fly-derived Leishmania promastigotes. PLOS Negl. Trop. Dis. 2019, 13, e0007288. [CrossRef]

32. Alcolea, P.J.A.; Alonso, A.; Domínguez, M.; Parro, V.; Jimenez, M.; Molina, R.; Larraga, V. Influence of the Microenvironment in the Transcriptome of Leishmania infantum Promastigotes: Sand Fly versus Culture. PLOS Neglected Trop. Dis. 2016, 10, e0004693. [CrossRef] [PubMed]

33. Alcolea, P.J.; Alonso, A.; Larraga, V. Rationale for selection of developmentally regulated genes as vaccine candidates against Leishmania infantum infection. Vaccine 2016, 34, 5474-5478. [CrossRef] [PubMed]

34. De Agüero, M.G.; Ganal-Vonarburg, S.C.; Fuhrer, T.; Rupp, S.; Uchimura, Y.; Li, H.; Steinert, A.; Heikenwalder, M.; Hapfelmeier S.; Sauer, U.; et al. The maternal microbiota drives early postnatal innate immune development. Science 2016, 351, 1296-1302. [CrossRef] [PubMed]

35. De Freitas, F.B.; Frouco, G.; Martins, C.; Ferreira, F. African swine fever virus encodes for an E2-ubiquitin conjugating enzyme that is mono- and di-ubiquitinated and required for viral replication cycle. Sci. Rep. 2018, 8, 3471. [CrossRef]

36. Pohl, C.; Dikic, I. Cellular quality control by the ubiquitin-proteasome system and autophagy. Science 2019, 366, 818-822. [CrossRef] [PubMed]

37. Deshaies, R.J.; Joazeiro, C.A. RING Domain E3 Ubiquitin Ligases. Annu. Rev. Biochem. 2009, 78, 399-434. [CrossRef] [PubMed]

38. Dawson, T.M.; Dawson, V.L. Molecular Pathways of Neurodegeneration in Parkinson's Disease. Science 2003, 302, 819-822. [CrossRef] [PubMed]

39. Hallengren, J.; Chen, P.-C.; Wilson, S.M. Neuronal Ubiquitin Homeostasis. Cell Biophys. 2013, 67, 67-73. [CrossRef]

40. Gardner, R.G.; Nelson, Z.W.; Gottschling, D.E. Degradation-Mediated Protein Quality Control in the Nucleus. Cell 2005, 120, 803-815. [CrossRef]

41. Muñoz, C.; Francisco, J.S.; Gutiérrez, B.; González, J. Role of the Ubiquitin-Proteasome Systems in the Biology and Virulence of Protozoan Parasites. BioMed Res. Int. 2015, 2015, 141526. [CrossRef]

42. Bhandari, D.; Guha, K.; Bhaduri, N.; Saha, P. Ubiquitination of mRNA cycling sequence binding protein from Leishmania donovani (LdCSBP) modulates the RNA endonuclease activity of its Smr domain. FEBS Lett. 2011, 585, 809-813. [CrossRef] [PubMed]

43. Kazemirad, E.; Mohebali, M.; Khadem-Erfan, M.B.; Hajjaran, H.; Hadighi, R.; Khamesipour, A.; Rezaie, S.; Saffari, M.; Raoofian, R.; Heidari, M. Overexpression of Ubiquitin and Amino Acid Permease Genes in Association with Antimony Resistance in Leishmania tropica Field Isolates. Korean J. Parasitol. 2013, 51, 413-419. [CrossRef]

44. González-Aseguinolaza, G.; Almazan, F.; Rodríguez, J.; Marquet, A.; Larraga, V. Cloning of the gp63 surface protease of Leishmania infantum: Differential post-translational modifications correlated with different infective forms. Biochim. Biophys. Acta (BBA)-Mol. Basis Dis. 1997, 1361, 92-102. [CrossRef]

45. Bradford, M.M. A rapid and sensitive method for the quantitation of microgram quantities of protein utilizing the principle of protein-dye binding. Anal Biochem. 1976, 72, 248-254. [CrossRef]

46. Laemmli, U.K. Cleavage of Structural Proteins during the Assembly of the Head of Bacteriophage T4. Nature 1970, 227, 680-685. [CrossRef] [PubMed]

47. Hannaert, V.; Opperdoes, F.R.; Michels, P.A. Comparison and Evolutionary Analysis of the Glycosomal Glyceraldehyde-3Phosphate Dehydrogenase from Different Kinetoplastida. J. Mol. Evol. 1998, 47, 728-738. [CrossRef]

48. Alzate, J.F.; Alvarez-Barrientos, A.; Gonzalez, V.M.; Jimenez-Ruiz, A. Heat-induced programmed cell death in Leishmania infantum is reverted by Bcl-X(L) expression. Apoptosis 2006, 11, 161-171. [CrossRef]

49. Alcolea, P.J.; Alonso, A.; García-Tabares, F.; Mena, M.D.C.; Ciordia, S.; Larraga, V. An Insight into the Constitutive Proteome Throughout Leishmania donovani Promastigote Growth and Differentiation. Int. Microbiol. 2018, 22, 143-154. [CrossRef]

50. Cristobo, I.; Larriba, M.J.; Ríos, V.D.L.; García, F.; Muñoz, A.; Casal, J.I. Proteomic analysis of 1 $\alpha$,25-Dihydroxyvitamin D3 action on human colon cancer cells reveals a link to splicing regulation. J. Proteom. 2011, 75, 384-397. [CrossRef]

51. Käll, L.; Canterbury, J.D.; Weston, J.; Noble, W.S.; MacCoss, M.J. Semi-supervised learning for peptide identification from shotgun proteomics datasets. Nat. Methods 2007, 4, 923-925. [CrossRef]

52. Buffet, P.A.; Sulahian, A.; Garin, Y.J.; Nassar, N.; Derouin, F. Culture microtitration: A sensitive method for quantifying Leishmania infantum in tissues of infected mice. Antimicrob. Agents Chemother. 1995, 39, 2167-2168. [CrossRef] [PubMed]

53. Livak, K.J.; Schmittgen, T.D. Analysis of relative gene expression data using real-time quantitative PCR and the 2(-Delta Delta C(T)) Method. Methods 2001, 25, 402-408. [CrossRef]

54. Sheng, Y.; Hong, J.H.; Doherty, R.; Srikumar, T.; Shloush, J.; Avvakumov, G.V.; Walker, J.R.; Xue, S.; Neculai, D.; Wan, J.W.; et al. A Human Ubiquitin Conjugating Enzyme (E2)-HECT E3 Ligase Structure-function Screen. Mol. Cell. Proteom. 2012, 11, 329-341. [CrossRef]

55. Merkley, N.; Shaw, G.S. Solution Structure of the Flexible Class II Ubiquitin-conjugating Enzyme Ubc1 Provides Insights for Polyubiquitin Chain Assembly. J. Biol. Chem. 2004, 279, 47139-47147. [CrossRef] [PubMed]

56. Besteiro, S.; Williams, R.; Morrison, L.S.; Coombs, G.H.; Mottram, J. Endosome Sorting and Autophagy Are Essential for Differentiation and Virulence of Leishmania major. J. Biol. Chem. 2006, 281, 11384-11396. [CrossRef] [PubMed] 
57. Goos, C.; DeJung, M.; Wehman, A.M.; M-Natus, E.; Schmidt, J.; Sunter, J.; Engstler, M.; Butter, F.; Kramer, S. Trypanosomes can initiate nuclear export co-transcriptionally. Nucleic Acids Res. 2018, 47, 266-282. [CrossRef] [PubMed]

58. Sharma, A.; Madhubala, R. Ubiquitin Conjugation of Open Reading Frame F DNA Vaccine Leads to Enhanced Cell-Mediated Immune Response and Induces Protection against Both Antimony-Susceptible and -Resistant Strains of Leishmania donovani. J. Immunol. 2009, 183, 7719-7731. [CrossRef]

59. Heidari, S.; Hajjaran, H.; Kazemi, B.; Gharechahi, J.; Mohebali, M.; Ranjbar, M.M.; Akhoundi, B.; Azarian, B.; Mirshahvaladi, S.; Raoofian, R. Identification of immunodominant proteins of Leishmania infantum by immunoproteomics to evaluate a recombinant multi-epitope designed antigen for serodiagnosis of human visceral leishmaniasis. Exp. Parasitol. 2021, 222, 108065. [CrossRef] 